\title{
Transgenic expression of Korean type hepatitis $C$ virus core protein and related mutants in mice
}

\author{
Ai-Guo Wang ${ }^{1,6}$, Hyung-Bae Moon ${ }^{2}$, \\ Young-Ho Lee ${ }^{3}$, Seong-Lan Yu, \\ Hyun-Jung Kwon ${ }^{1}$, Ying-Hao Han ${ }^{1}$, \\ Wan Fang ${ }^{1}$, Tae-Hoon Lee ${ }^{4}$, \\ Kyung-Lib Jang ${ }^{5}$, Sang-Keun Kim ${ }^{6}$, \\ Dae-Yeul $\mathrm{Yu}^{1^{1 *}}$ and Dong-Seok Lee ${ }^{1 *, 7}$ \\ ${ }^{1}$ Laboratory of Human Genomics \\ Korea Research Institute of Bioscience and Biotechnology (KRIBB) \\ Daejeon 305-806 \\ ${ }^{2}$ Department of Pathology and Institute of Medical Science \\ Wonkwang University, School of Medicine \\ Iksan 570-749 \\ ${ }^{3}$ Department of Anatomy \\ College of Medicine, Chungnam National University \\ Daejeon 301-131 \\ ${ }^{4}$ Department of Oral Biochemistry \\ College of Dentistry, Chonnam National University \\ Gwangju 500-757 \\ ${ }^{5}$ Department of Microbiology \\ College of Natural Sciences, Pusan National Unversity \\ Pusan 609-735, Korea \\ ${ }^{6}$ College of Veterinary Medicine \\ Chungnam National University \\ Daejeon 305-764, Korea \\ ${ }^{7}$ Corresponding author: Tel, 82-42-860-4349; \\ Fax, 82-42-860-4608; E-mail, lee10@kribb.re.kr \\ *Theses anthors contributed equally to this work.
}

Accepted 9 December 2004

Abbreviations: HCC, hepatocellular carcinoma; HCV, hepatitis C virus; LCD, liver cell dysplasia

\footnotetext{
Abstract

Hepatitis C virus (HCV) is a major causative agent in liver disease. In order to investigate if Korean type HCV core protein and its related mutants, S99Q and S116I, are cytopathic to liver, three types of transgenic mice were established. The expression of transgenes was confirmed by HCV specific RT-PCR and Western immunoblotting. The livers of all wild type core and S116I transgenic lineages remained largely histologically normal. However, the livers of the S99Q transgenic mice showed significant high level of cell dysplasia associated with the trans-
}

gene expression in hepatocytes largely located around the central veins by in situ hybridization analysis. In conclusion, the mutant HCV core protein at $S 99 Q$ may contribute to the progress of HCV induced liver disease.

Keywords: core; dysplasia; hepatitis C virus; transgenic mice

\section{Introduction}

It is well known that the hepatitis $C$ virus (HCV), a positive-stranded RNA virus of the Flaviviridae family, is a major causative agent of chronic hepatitis, cirrhosis, and hepatocellular carcinoma (HCC) throughout the world (Kuo et al., 1989; Saito et al., 1990; Shiratori et al., 1995). However, the mechanisms by which HCV infection promotes the development of liver disease remain largely unknown. Accumulating evidence suggests the direct or indirect involvement of viral proteins, especially the core protein, in liver carcinogenesis. The roles of the HCV core protein remain as unclear issues due to conflicting findings that have been reported (Watashi et al., 2003).

In Korea, HCV infections are frequently observed in patients with cirrhosis with $16.5 \%$ detected for $\mathrm{HCV}$ RNA positive and $91.7 \%$ for anti-HCV positive. The combined rate of $\mathrm{HCC}$ was significantly higher in $\mathrm{HCV}$ patients than non-virus infected patients (Kwon et al., 2000). The Korean type HCV genotypes have a high sequence homology with the Japanese isolates (Jang et al., 1993), which has been shown to have an important function in hepatocarcinogenesis when overexpressed in the mouse liver (Moriya et al., 1998). In addition, our previously published data and that by other groups have shown that a comparison of the phosphorylation intensities of the wild type and Serine mutants indicate that Ser99 and Ser116 of the core protein were the major phosphorylation sites for PKC and PKA, respectively. Modification of the core protein by phosphorylation may influence core functions (Shih et al., 1995; Jung et al., 2001; Lu et al., 2002).

The objectives of this study was to investigate whether the Korean type HCV core protein and its mutation type, Ser99 and Ser116, play a role in the development of liver disease in vivo. 


\section{Materials and Methods}

\section{Construction transgenes and transgenic lineages generation}

Three types of core genes [wild type $(K)$, mutant Ser99 to glutamine (S99Q), mutant Ser116 to isoleucine (S116I)] DNA were subcloned into plasmid pHEX (Yu et al., 1999) to replace HBX DNA. Injectable DNA was obtained by the removal from the plasmid at the EcoRI and HindIII restriction-endonuclease digestion sites. DNA was microinjected into fertilized mouse eggs of inbred C57BL/6J, and the injected eggs were transferred into pseudopregnant recipients, as previously described (Yu et al., 1999). Potential founders were analyzed by the PCR and Southern blots from tail DNA.

\section{RT-PCR}

Total RNA was isolated from mouse tissues using the TRIzol reagent (Invitrogen, Carlsbad CA). RT-PCR was performed to detect the expression of transgenes in the tissues of transgenic mice. The RT step was carried out using a Reverse Transcription Kit (Promega Corp., WI) according to the manufacturer's instructions. The PCR step was performed using AccPrime $^{\mathrm{TM}}$ Taq DNA polymerase (Invitrogen Corp., Carlsbad, CA) according to manufacturer's instructions. The primers used in the PCR step were: sense primer 5'-CTTATCGGCACCGACAACTC-3' and antisense primer 5'-CTGTTGCATAGTTAACGCCGT-3'.

\section{Western blotting}

Liver tissue was homogenized and lysed in lysis buffer. Equal amounts $(30 \mu \mathrm{g})$ of proteins were resolved by SDS-PAGE and transferred to a polyvinylidene difluoride (PVDF) membrane (Millipore Corp, Badford, MA). The membranes were probed with primary and secondary antibodies. Positive bands were detected by means of an enhanced chemiluminescence (ECL) system (Pierce, Rochford, IL). GAPDH was used as an evidence for the protein loading controls. The antibodies used in Western immunoblotting were an anti-rabbit core polyclonal antibody, previously described (Lo et al., 1995), and horseradish peroxidase (HRP)-conjugated goat antirabbit IgG (Santa Cruz Biotech., Santa Cruz, CA).

\section{Histological analysis and in situ hybridization}

Mice were sacrificed between 10 and 22 months of age, and major organs and tissues, including livers were removed, fixed in $10 \%$ neutral buffered formalin and embedded in paraffin, $4 \mu \mathrm{m}$ in thick sections obtained, which were stained with hematoxylin-eosin. Morphologic findings of dysplastic liver cells were characterized by cellular enlargement, nuclear pleomorphism, multinucleation and the presence of large nucleoli, occurring in groups (Watanabe et al., 1983; Cho et al., 2003).

In situ hybridization for the core was performed with digoxigenin-labeled riboprobes using previously described methods (Han et al., 2003). Core antisense and sense riboprobes were prepared from $421 \mathrm{bp}$ $\mathrm{HCV}$ core cDNA fragments cloned pBluescript SK+ vector (Stratagene, La Jolla, CA) flanked by the T3 and $T 7$ promotors. For the antisense riboprobes of the core, the plasmid was linearized with $X b a l$ and transcribed with T7 RNA polymerase; for the sense probe for the core, the plasmid was linearized with HindIII and transcribed with T3 RNA polymerase.

\section{Statistical analysis}

Experimental differences were tested for statistical significance using the chi-square test. $P$ value of $<$ 0.05 was considered to be significant.

\section{Results}

\section{Plasmid constructs}

Previously published data indicated that a mutation at S99Q or S116l affected the behavior of the core protein in HuH-7 cells (Shih et al., 1995). When the mutant core was transfected to NIH3T3 cells, the efficiency of transformation was significantly higher than that of the wild type (data not shown). To examine these results in vivo, three types of core transgenic vectors were constructed. One was the wild type core (Korean type), another was mutant 99 in which serine-99 was substituted with glutamine and the third was mutant 116 in which serine-116 was substituted with isoleucine (Figure 1 and $2 \mathrm{~A}$ ).

\section{Establishment of transgenic lines and expression of transgenes in transgenic mice}

Two $\mathrm{K}$ transgenic lines (\#27, \#31), three 99 transgenic lines (\#29, \#38, \#56) and one 116 transgenic line $(\# 60)$ were produced. The transgenes were expressed in liver tissues (Figure 2B) and also in other organs (data not shown) of transgenic mouse by RT-PCR analysis. Western immunoblotting further confirmed that the core and its mutant types were substantially expressed in liver tissues (Figure 2C). In order to investigate the location of core gene expression, in situ hybridization was performed using the livers of the 99 line mice. Core mRNA was expressed at relatively high levels in hepatocytes around the central veins in hepatic tissue (Figure 3D), but not expressed in the hepatic tissue of the normal littermates (Figure 3C). 
A

HCV genotype $1 \mathrm{~b}$ atgagcacoga atcctaaacc tcaaagaaaa accaaacgta acaccopecg gegcccacag gacgtcaagt Korean type core atgagcacaa atcctaaacc tcaaagaaaa accaaacgta acaccalecg cegcccacag gacgtcaagt

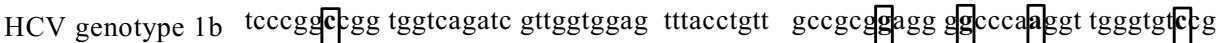
Korean type core tccegggegg tggtcagatc gttggtggag tttacctgtt gccgcocagg gecccaggt tgggtgtg $\mathrm{g}$

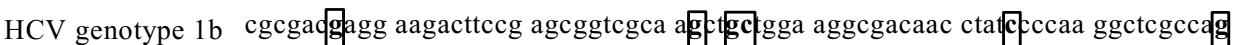
Korean type core cgcgadthgg aagacttccg agcggtcgca actegtgga aggegacaac ctatteccaa ggctcgccaa

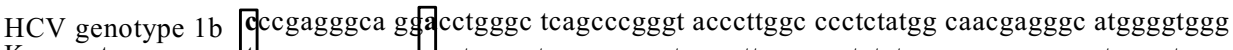
Korean type core tecgagggca gggectggge tcagccegggt accettggc ccctctatgg caacgaggge atggggtggg

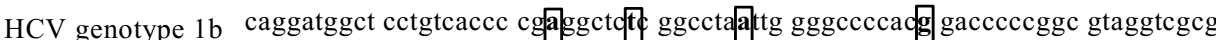

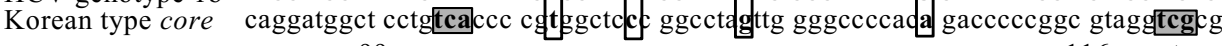
mutant $99 \rightarrow$ cag $\quad$ mutant $116 \rightarrow$ atc

$\mathrm{HCV}$ genotype $1 \mathrm{~b}$ taatttgggt aa a ptcatcg a caccctcac atgeggettc eccgacctca tggggtacat tcegctcgtc Korean type core taatttgggt aaggtcatcg at tecctcac atgeggettc gegacctca tggggtacat tccgctcgtc

$\mathrm{HCV}$ genotype $1 \mathrm{~b}$ ggcgecccc tagggggegc tgccagggec ctggcacatg gtgtccgggt tctggaggac ggegtopact Korean type core ggcgccccc tagggggegc tgccagggcc ctggcacatg gtgtccgggt tctggaggac ggcgtt aact

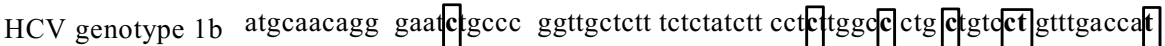
Korean type core atgcaacagg gaatt tgecc ggttgctctt tctctatctt cct t tggdt ctg ttgtd tg gtttgaccac

HCV genotype $1 \mathrm{~b}$ cccasetteg gct Korean type core cccauttct gct ta

B HCV genotype $1 b$ Korean type core

M S T N P K P Q R K T K R N T R R P Q D V K F P A G Q IV G G V Y L L P R R M S T N P K P Q R K T K R N T N R P Q D V K F P G G Q I V G G V Y L L P R R

HCV genotype $1 b$ Korean type core

GPRLG R A T R K T S ER S Q A A R R Q P I P K A R OP E R T W A Q P G A P G L G V R A T R K T S E R S Q P R G R R Q P I P K A R Q S E G R A W A Q P G

HCV genotype $1 b$ Korean type core

Y P W P L Y G N E G M GW A GW L L S PRGSRPNW G P T D R R R S R L Y P W P L Y G N E G M G W A W L L S P R G R P S W G P T D P R R R S R N L mutant $99 \rightarrow \mathbf{Q}$ mutant $116 \rightarrow$ I

HCV genotype $1 b$ Korean type core

G K VID T L T C G P D L M G Y IP L V G A P L G G A A R A L A H G VR V LE D G K V I D T L T C G A D L M G Y I P L V G A P L G G A A R A L A H G V R V L E D

HCV genotype $1 b$ Korean type core

G V N Y A T G N L P G C S F S I F L L A L L S G L T T P V S A G V N Y A T G N L P G C S F S I F L L A L L SCL T I P A S A

Figure 1. Comparison of Core transgene of Korean type $\mathrm{HCV}$ with that of $\mathrm{HCV}$ genotype 1b. (A) Comparison of the Korean HCV core sequence with that of HCV genotype $1 \mathrm{~b}$. Mutant 99 and 116 transgenes are substituted as follows: TCA to CAG and TCG to ATC, respectively (indicated by shade squares). The sequence is shown in DNA format (T residues instead of $U$ residues). (B) Comparison of Korean HCV core protein sequence with that of HCV genotype $1 b$. The serine 99 and serine 116 are substituted by glutamine and isoleucine in the mutant types, respectively.

Table 1. Histopathologic findings in livers of $K, 99,116$ transgenic mice and wild type mice.

\begin{tabular}{lrrrr} 
& Wild type & k & 99 & 116 \\
\hline Fatty change (\%) & $10 / 30(33.3)$ & $7 / 22(31.8)$ & $11 / 29(37.9)$ & $1 / 10(10)$ \\
Dysplasia (\%) & $1 / 30(3.3)$ & $1 / 22(4.5)$ & $7 / 29(24.1)^{*}$ & $0 / 10$ \\
Tumor (\%) & $0 / 30$ & $1 / 22(4.5)$ & $0 / 29$ & $0 / 10$ \\
\hline
\end{tabular}

Note: ${ }^{*}$ significantly different compared with $\mathrm{K}$ and 116 transgenic mice and wild type mice $(P<0.05)$. 
A

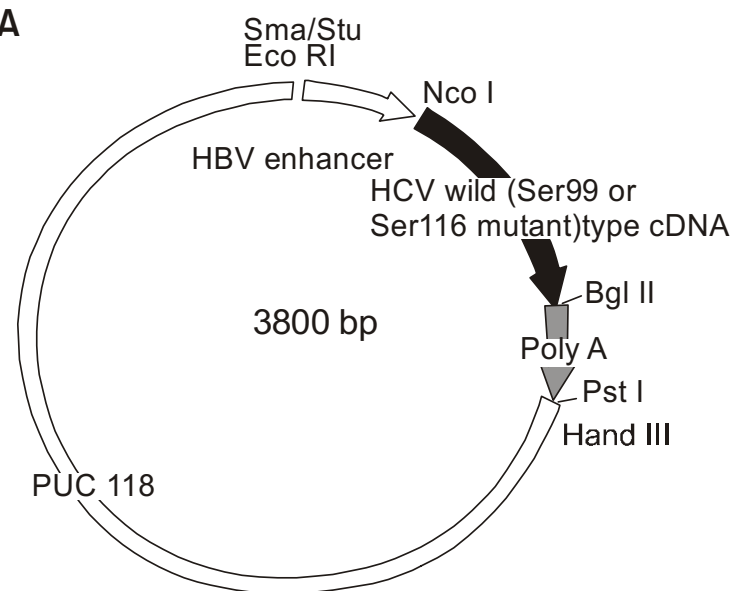

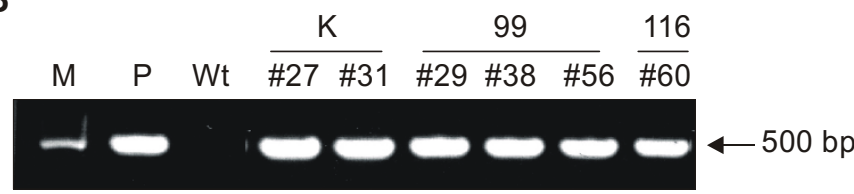

C

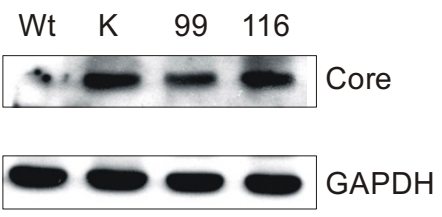

Figure 2. Construction of HCV core transgenes expression vectors and identification of transgenes expression. (A) The HBX gene in plasmid pHEX was substituted at the restriction enzyme sites $\mathrm{Ncol}$ and Bglll by the transgenes, Korean type HCV core wild type, mutant 99 of Korean HCV core and mutant 116 of Korean HCV core, respectively. (B) RT-PCR was performed using total RNA extracted from liver tissues. The transgenes were all expressed in liver tissues in the established transgenic lines. $(C)$ The expression of the core and its mutant proteins in livers of transgenic mice were detected by Western immunoblotting. GAPDH was used as a quantity control. M: maker; Wt, wild type mice; P: positive control; K: wild core transgenic mice; 116: 116 transgenic mice; 99: 99 transgenic mice.

\section{Pathological assay of transgenic mice}

Fatty changes and chronic inflammatory cell infiltration were found in both wild type and transgenic mice, but there were no significant differences between the wild type and transgenic mice. Dysplastic liver cells were significant highly found in $24.1 \%$ of the 99 transgenic mice compared with wild type mice (Table 1). Interestingly, dysplastic cells were mainly appeared around the central vein in hepatic tissue of the 99 line mice (Figure $3 \mathrm{~B}$ ) but not detected in normal littermates (Figure $3 \mathrm{~A}$ ). This is directly associated with the 99 transgene expression (Figure 3D). These findings indicate that the mutant Ser99 protein is cytopathic to hepatocytes. There were no specific pathologies in other organs and tissues including lung, heart, kidney, spleen and brain in either the wild type or the transgenic mice.

\section{Discussion}

Transgenic animal models have contributed important information on hepatitis virus-mediated pathogenesis (Hanahan, 1988; Chisari, 1995; Moriwaki, 2002). To examine if the Korean type core protein and mutants, thereof, 99 and 116, contribute to liver diseases, we successfully established three types transgenic models that express the core protein and its mutants thereof.

Collecting the published data, it seems only the expression of core gene from Japanese genotype $1 \mathrm{~b}$ HCV under the genetic background of C57BL/6J inbred mouse can induce the hepatic alterations
(Moriya et al., 1997; Moriya et al., 1998). However, transgenic mice expressing core protein established using other genotype of HCV (Kawamura et al., 1997) or under other genetic background mouse strain (Pasquinelli et al., 1997) failed to generate hepatic alteration. However, in our wild core transgenic mice, we were unable to detect statistically significant pathological changes in the livers between transgenic and normal littermates. This suggests that, while the Korean type HCV virus is closely related to Japanese types, it is not directly cytopathic in our animal model. It has been suggested that the core protein cooperates with nonstructural proteins of $\mathrm{HCV}$, to induce the development of liver cancer (Lerat et al., 2002). In Korea, the occurrence of HCV related hepatocarcinogenesis is significantly higher than non-virus related liver cancer. This indicates that Korean type $\mathrm{HCV}$ is a main causative agent in $\mathrm{HCC}$ development. Even the core is not directly cytopathic in our transgenic model. It may, however, cooperate with other virus proteins.

Even though our in vitro transfection with the three types of transgenes suggested that the 99 and 116 mutant types were able to efficiently transform the NIH3T3 cells, our in vivo experiments using transgenic models failed to detect any hepatic tumor development. However, a significantly higher liver cell dysplasia (LCD) was detected in the Ser99 mutant transgenic lines and the location of LCD are directly associated with the location of transgene expression. The term LCD was first coined by Anthony (Anthony et al., 1973). Presence of LCD was identified in a group of patients at high risk for the development of 

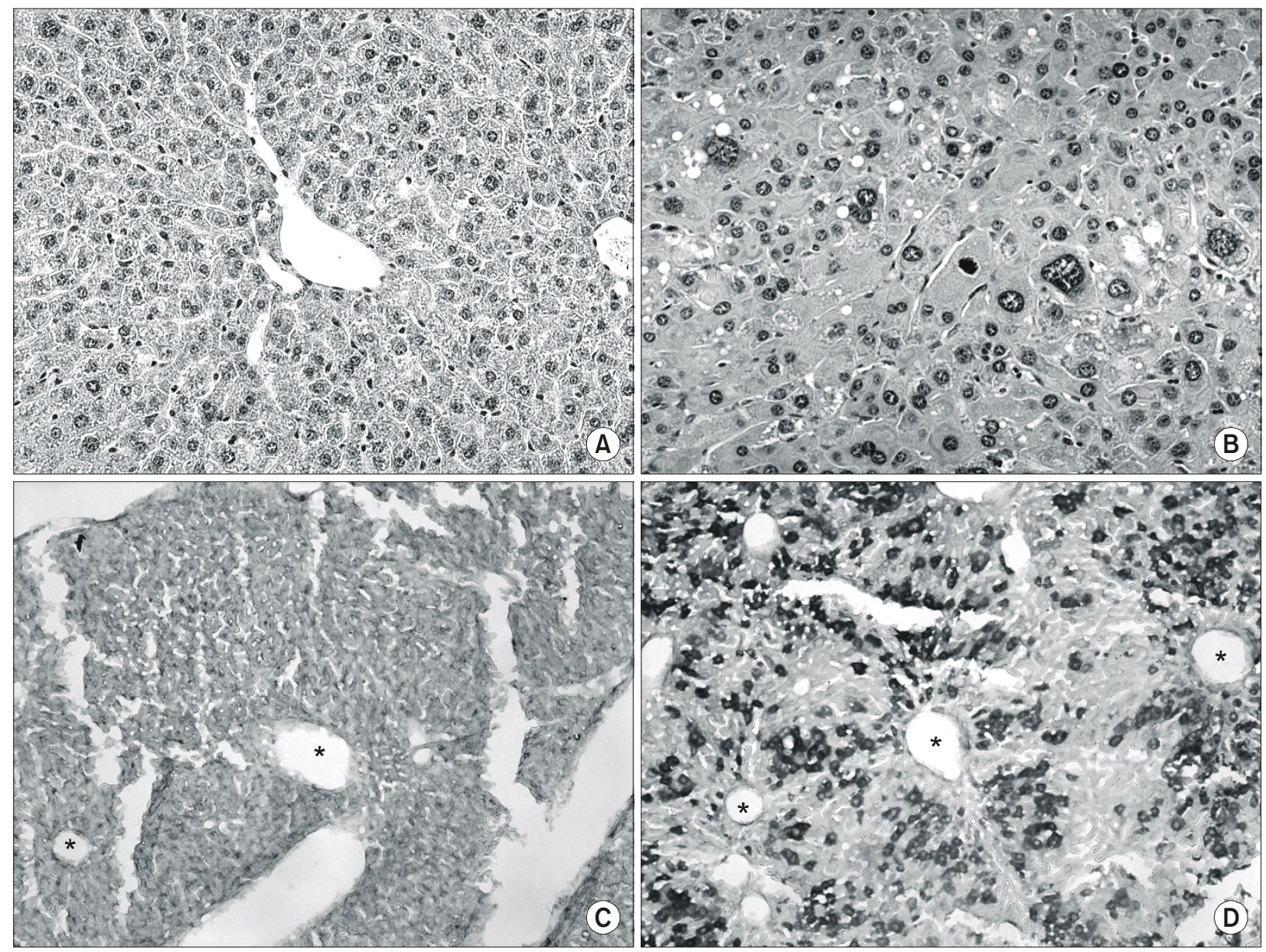

Figure 3. Histopathologic changes and transgene expression in the liver of 99 transgenic mice and normal littermate. A-B, Hematoxylin-eosin staining. (A) The liver of normal littermate was histologically normal. (B) Dysplastic cells characterized by pleomorphism, nucleoli and multinucleation were detected in the liver of 99 transgenic mice. C-D, Analysis of the expression of the transgene by in situ hybridization. (C) The expression of the transgene was not detected in the liver tissues of normal littermate. (D) The expression of the transgene was detected around the central veins in the liver of the 99 transgenic mice. Magnification: $200 \times$ (A, B), 100× (C, D); Age: 13 months old; *indicates central veins.

HCC. Although a primary investigation demonstrated that LCD was originally linked to hepatitis B infections, it was later reported that $42.5 \%$ of patients with non- $A$, non-B hepatitis were most often associated with cirrhosis (Kamal G. Ishak, 2001). This indicates that the mutant at serine 99 was able to influence the functions of core protein significantly in vivo. This strongly suggests that clinically, patients carrying serine 99 mutant genotype of the HCV may have a greater chance of developing HCC. In addition, our previously published paper showed that core expression in liver tissue can activate the transcription of p21 in a p53 independent pathway (Kwun et al., 2003). While the mechanisms involved is largely unknown, our in vivo experiments confirmed the in vitro results and the opposing effects of core protein on the transcription of p21 might be important in understanding the progression of hepatic disease in HCV positive patients.

In conclusion, that the 99 mutant type core induced significantly higher levels of LCD in liver tissues indicated that the mutant at Serine 99 could leat to liver diseases in $\mathrm{HCV}$ positive patients.

\section{Acknowledgement}

This work was supported by the $21^{\text {st }}$ Century Frontier program in Functional Human Genome Project of Korea Grant No. HGC0300324 and the Ministry of Health and Welfare of Korea Grant No. 02-PJ2-PG1CH12-0002. 


\section{References}

Chisari FV. Hepatitis B virus transgenic mice: insights into the virus and the disease. Hepatology 1995;22:1316-25

Cho CH, Lee SY, Shin HS, Philipson KD, Lee CO. Partial rescue of the $\mathrm{Na}(+)-\mathrm{Ca}(2+)$ exchanger (NCX1) knock-out mouse by transgenic expression of NCX1. Exp Mol Med 2003;35:125-35

Han SH, Jeon JH, Ju HR, Jung U, Kim KY, Yoo HS, Lee $\mathrm{YH}$, Song KS, Hwang HM, Na YS, Yang Y, Lee KN, Choi I. VDUP1 upregulated by TGF-beta1 and 1,25-dihydorxyvitamin D3 inhibits tumor cell growth by blocking cell-cycle progression. Oncogene 2003;22:4035-46

Hanahan D. Dissecting multistep tumorigenesis in transgenic mice. Annu Rev Genet 1988;22:479-519

Jang KL, Cho YG, Song MK, Kim CM, Lee DS, Sung YC. Genetic variability in the envelope region of hepatitis $C$ virus isolated from Korean patients with non-A, non-B hepatitis. Mol. Cells 1993;3:419-426

Jung EY, Lee MN, Yang HY, Yu D, Jang KL. The repressive activity of hepatitis $C$ virus core protein on the transcription of p21(waf1) is regulated by protein kinase A-mediated phosphorylation. Virus Res 2001;79:109-15

Kamal G. Ishak ZDG, J. Thomas Stocker. Atlas of tumor pathology, Tumors of the liver and intrahepatic bile ducts. Armed Forces Institute of Pathology, Washington, DC, USA, 2001;3rd ed.

Kawamura T, Furusaka A, Koziel MJ, Chung RT, Wang TC, Schmidt EV, Liang TJ. Transgenic expression of hepatitis C virus structural proteins in the mouse. Hepatology 1997; $25: 1014-21$

Kuo G, Choo QL, Alter HJ, Gitnick GL, Redeker AG, Purcell $\mathrm{RH}$, Miyamura T, Dienstag JL, Alter MJ, Stevens CE, et al. An assay for circulating antibodies to a major etiologic virus of human non-A, non-B hepatitis. Science 1989;244:362-4

Kwon SY, Ahn MS, Chang HJ. Clinical significance of hepatitis $C$ virus infection to alcoholics with cirrhosis in Korea. J Gastroenterol Hepatol 2000;15:1282-6

Kwun HJ, Jang KL. Dual effects of hepatitis C virus Core protein on the transcription of cyclin-dependent kinase inhibitor p21 gene. J Viral Hepat 2003;10:249-55

Lerat $\mathrm{H}$, Honda $M$, Beard MR, Loesch $K$, Sun J, Yang $Y$, Okuda M, Gosert R, Xiao SY, Weinman SA, Lemon SM. Steatosis and liver cancer in transgenic mice expressing the structural and nonstructural proteins of hepatitis C virus. Gastroenterology 2002;122:352-65
Lo SY, Masiarz F, Hwang SB, Lai MM, Ou JH. Differential subcellular localization of hepatitis $C$ virus core gene products. Virology 1995;213:455-61

Lu W, Ou JH. Phosphorylation of hepatitis C virus core protein by protein kinase $\mathrm{A}$ and protein kinase $\mathrm{C}$. Virology 2002;300:20-30

Moriwaki $H$. Prevention of liver cancer: basic and clinical aspects. Exp Mol Med 2002;34:319-25

Moriya K, Yotsuyanagi H, Shintani Y, Fujie H, Ishibashi K, Matsuura $Y$, Miyamura T, Koike K. Hepatitis C virus core protein induces hepatic steatosis in transgenic mice. J Gen Virol 1997;78(Pt 7):1527-31

Moriya K, Fujie H, Shintani $Y$, Yotsuyanagi H, Tsutsumi T, Ishibashi K, Matsuura Y, Kimura S, Miyamura T, Koike K. The core protein of hepatitis $C$ virus induces hepatocellular carcinoma in transgenic mice. Nat Med 1998;4:1065-7

Pasquinelli C, Shoenberger JM, Chung J, Chang KM, Guidotti LG, Selby M, Berger K, Lesniewski R, Houghton M, Chisari FV. Hepatitis C virus core and E2 protein expression in transgenic mice. Hepatology 1997;25:719-27

Saito I, Miyamura T, Ohbayashi A, Harada H, Katayama T, Kikuchi S, Watanabe $Y$, Koi S, Onji M, Ohta $Y$, et al. Hepatitis $C$ virus infection is associated with the development of hepatocellular carcinoma. Proc Natl Acad Sci U S A 1990;87:6547-9

Shih $\mathrm{CM}$, Chen CM, Chen SY, Lee YH. Modulation of the trans-suppression activity of hepatitis $C$ virus core protein by phosphorylation. J Virol 1995;69:1160-71

Shiratori $Y$, Shiina S, Imamura M, Kato N, Kanai F, Okudaira T, Teratani T, Tohgo G, Toda N, Ohashi M, et al. Characteristic difference of hepatocellular carcinoma between hepatitis B- and C-viral infection in Japan. Hepatology 1995;22:1027-33

Watanabe S, Okita K, Harada T, Kodama T, Numa $Y$, Takemoto T, Takahashi T. Morphologic studies of the liver cell dysplasia. Cancer 1983;51:2197-205

Watashi K, Shimotohno K. The roles of hepatitis C virus proteins in modulation of cellular functions: $\mathrm{A}$ novel action mechanism of the HCV core protein on gene regulation by nuclear hormone receptors. Cancer Sci 2003;94:937-43

Yu DY, Moon HB, Son JK, Jeong S, Yu SL, Yoon H, Han YM, Lee CS, Park JS, Lee CH, Hyun BH, Murakami S, Lee $\mathrm{KK}$. Incidence of hepatocellular carcinoma in transgenic mice expressing the hepatitis B virus X-protein. J Hepatol 1999;31:123-32 